Editors' Note: In "Monitoring long-term efficacy of fampridine in gait-impaired patients with multiple sclerosis," authors Filli et al. showed that prolonged-release fampridine improved walking speed, endurance, and self-perceived ambulatory function in patients with multiple sclerosis (MS). Furthermore, patients showed additional drug responsiveness with longterm treatment. Commenting on the article, Dr. Davis asks whether there is a correlation between increased fampridine responsiveness over time and cotreatment with natalizumab. He notes that $32 \%$ of the patients studied were also treated with natalizumab. Since the latter decreases disability in MS, it might increase the conduction safety factor sufficiently to restore impulse conduction in blocked axons and increase the efficacy of fampridine. To address Dr. Davis' comments, authors Filli et al. quantify the long-term responsiveness to fampridine of 6 patients with MS cotreated with natalizumab over a period of 2 years. They did not find an increased benefit with respect to walking function in patients treated with natalizumab vs other study participants. However, the number was small and studies with larger cohorts are needed. The editorial "A model for predicting the growth of unruptured intracranial aneurysms: Beyond fortune telling" addressed the article by Backes et al., "ELAPSS score for prediction of risk of growth of unruptured intracranial aneurysms." ELAPSS (earlier subarachnoid hemorrhage, location of the aneurysm, age $>60$ years, population, size of the aneurysm, and shape of the aneurysm) is a tool developed to predict the growth of unruptured aneurysms using a weighted composite of patient- and aneurysm-specific characteristics. Editorialists Ding and Etminan believe that ELAPSS is a useful tool to predict risk of growth of unruptured intracranial aneurysms but that the management strategy for these lesions must be supplemented by numerous patient- and aneurysm-specific characteristics not included in the scoring system. Commenting on the editorial, Dr. Munakomi suggests evaluating the role of computational flow dynamics (CFD) to assess further the aneurysm-specific rupture risk. Dr. Ding agrees that CFD may, in the future, provide valuable insight into the rupture risk of unruptured aneurysms, but warns that CFD models require rigorous and prospective validation before they can be applied to clinical decision-making for unruptured aneurysms.

-Chafic Karam, MD, and Robert C. Griggs, MD

\section{LETTER RE: MONITORING LONG-TERM \\ EFFICACY OF FAMPRIDINE IN GAIT-IMPAIRED PATIENTS WITH MULTIPLE SCLEROSIS}

Floyd A. Davis, Los Angeles: I read the article by Filli et al. ${ }^{1}$ with great interest. The authors reported that the responsiveness (efficacy) of prolonged-release fampridine for improving walking in multiple sclerosis (MS) increases over time. ${ }^{1}$ While the underlying mechanism is not known, its understanding might provide important insight for enhancing the efficacy of fampridine.

Thirty-two percent of the 53 patients studied were concomitantly treated with natalizumab. ${ }^{1}$ In addition to decreasing progression of disability, natalizumab improves disability in MS. ${ }^{2,3}$ This indicates that natalizumab can increase the conduction safety factor sufficiently to restore impulse conduction in blocked demyelinated axons. In cases in which increases in the conduction safety factor are insufficient to restore conduction in blocked axons, the efficacy of fampridine would increase due to the decrease in the severity of conduction block. This is also the basis for the increased efficacy of fampridine in temperaturesensitive patients with MS. ${ }^{4}$ This could explain, at least in part, the increased responsiveness of prolonged release fampridine over time. It would be of interest to know if there is a correlation between increased fampridine responsiveness over time and treatment with natalizumab.

1. Filli L, Zorner B, Kapitza S, et al. Monitoring long-term efficacy of fampridine in gait-impaired patients with multiple sclerosis. Neurology 2017;88:832-841.

2. Balcer LJ, Galetta SL, Polman CH, et al. Low-contrast acuity measures visual improvement in phase 3 trial of natalizumab in relapsing MS. J Neurol Sci 2012;318: 119-124.

3. Voloshyna N, Havrdova E, Hutchinson M, et al. Natalizumab improves ambulation in relapsing-remitting multiple sclerosis: results from the prospective TIMER study and a retrospective analysis of AFFIRM. Eur J Neurol 2015; 22:570-577.

4. Davis FA, Stefoski D, Rush J. Orally administered 4-aminopyridine improves clinical signs in multiple sclerosis. Ann Neurol 1990;27:186-192.

(C) 2017 American Academy of Neurology 
AUTHOR RESPONSE: MONITORING LONG-TERM EFFICACY OF FAMPRIDINE IN GAIT-IMPAIRED PATIENTS WITH MULTIPLE SCLEROSIS

Linard Filli, Björn Zörner, Tim Killeen, Zurich; Michael Linnebank, Hagen, Germany: Encouraged by Dr. Davis' insightful comment on our article, we retrospectively quantified the long-term responsiveness to fampridine of the patients with multiple sclerosis in our sample cotreated with natalizumab over a period of 2 years. Of 17 patients (32\%) treated with natalizumab at the screening visit, only 6 were still receiving treatment with natalizumab 2 years later; natalizumab was stopped in 5 patients and a further 6 discontinued the study. Monitoring the efficacy of fampridine over 2 years in the 6 patients concomitantly treated with natalizumab did not reveal an increased benefit with respect to walking function compared to the other study participants. Patients cotreated with natalizumab improved by $5.4 \%$ in maximal walking speed (vs 3.0\% in the rest of the population) and by $0.4 \%$ in walking endurance (vs 4.6\%) and demonstrated no difference in self-perceived walking ability (vs 6.5 points improvement in the rest of the population). This post hoc analysis is obviously limited by the small number of subjects. Dr. Davis' hypothesis and other potential mechanisms, discussed in our article, ${ }^{1}$ underlying the observed increased responsiveness to fampridine over time should be investigated in future studies with larger cohorts and of sufficient statistical power.

1. Filli L, Zorner B, Kapitza S, et al. Monitoring long-term efficacy of fampridine in gait-impaired patients with multiple sclerosis. Neurology 2017;88:832-841.

CC 2017 American Academy of Neurology

LETTER RE: A MODEL FOR PREDICTING THE GROWTH OF UNRUPTURED INTRACRANIAL ANEURYSMS: BEYOND FORTUNE TELLING

Sunil Munakomi, Biratnagar, Nepal: I read with interest the article by Backes et al., ${ }^{1}$ which considered risk factors for rupture of intracranial aneurysms. This article could change the treatment of unruptured aneurysms. In addition to the variables studied in this article, there is recent work evaluating the role of computational flow dynamics when assessing aneurysm-specific rupture risk. ${ }^{2}$ Future studies that include this entity might improve the ability to assess rupture risk.

1. Backes D, Rinkel GJ, Greving JP, et al. ELAPSS score for prediction of risk of growth of unruptured intracranial aneurysms. Neurology 2017;88:16001606.

2. Frosen J. Flow dynamics of aneurysm growth and rupture: challenges for the development of computational flow dynamics as a diagnostic tool to detect ruptureprone aneurysms. Acta Neurochir Suppl 2016;123: 89-95.

(C) 2017 American Academy of Neurology

\section{EDITORIALIST RESPONSE: A MODEL FOR PREDICTING THE GROWTH OF UNRUPTURED INTRACRANIAL ANEURYSMS: BEYOND FORTUNE TELLING}

Dale Ding, Phoenix, AZ: I thank Dr. Munakomi for the comments on the prediction of unruptured intracranial aneurysms. I agree that computational fluid dynamics (CFD) may provide valuable insight into the rupture risk of unruptured aneurysms, in addition to currently known patient- and aneurysm-specific predictive factors. However, CFD models require rigorous and prospective validation before they can be applied to clinical decision-making for patients with unruptured aneurysm. Until such time, we must rely on the wisdom of experienced cerebrovascular physicians and published data from high-volume aneurysm treatment centers to extrapolate the risk to benefit ratio of intervention vs conservative management for unruptured aneurysms.

(C) 2017 American Academy of Neurology

\section{CORRECTION}

\section{Motor neuron disease in patients with HIV infection}

In the abstract "Motor neuron disease in patients with HIV infection" by P. Lorenzoni et al., ${ }^{1}$ there is an error in the third author's last name, which should have read "Giuliano Dalledone" rather than "Dalladone" as originally published. The authors regret the error.

\section{REFERENCE}

1. Lorenzoni P, Ducci R, Dalledone G, et al. Motor neuron disease in patients with HIV infection. Neurology 2017; 88:P2.305. Abstract. 


\section{Neurology}

\section{Motor neuron disease in patients with HIV infection \\ Neurology 2017;89;1200 \\ DOI 10.1212/WNL.0000000000004449}

This information is current as of September 11, 2017

\section{Updated Information \&} Services

Permissions \& Licensing

Reprints including high resolution figures, can be found at: http://n.neurology.org/content/89/11/1200.4.full

Information about reproducing this article in parts (figures,tables) or in its entirety can be found online at:

http://www.neurology.org/about/about_the_journal\#permissions

Information about ordering reprints can be found online:

http://n.neurology.org/subscribers/advertise

Neurology ${ }^{\circledR}$ is the official journal of the American Academy of Neurology. Published continuously since 1951, it is now a weekly with 48 issues per year. Copyright () 2017 American Academy of Neurology. All rights reserved. Print ISSN: 0028-3878. Online ISSN: 1526-632X.

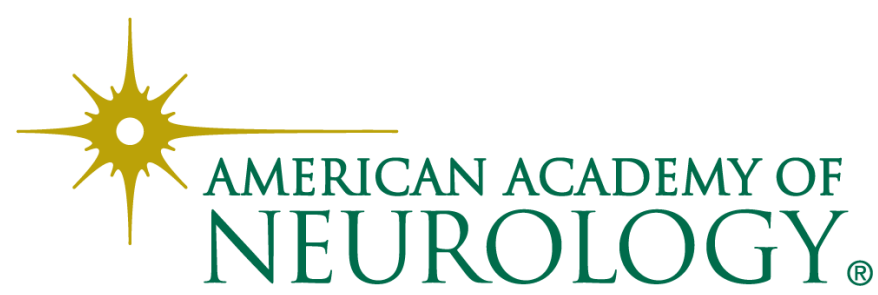

